\title{
ARIS Enterprise Architecture's Usage Reviews
}

\author{
Saiedeh Ghatrei
}

\begin{abstract}
Most organizations feel the need to have enterprise architecture's software. However, selecting the most appropriate software for any organization needs accuracy and sufficient information. We want to review ARIS Software as enterprise architecture software and its position among other softwares. ARIS modeling methods and tools is using hierarchical analysis for analyzing the actual values. It is also very critical that before implementation and testing of models to ensure about correct performance. ARIS gives users a facility that shows the accuracy of BPMN model's performance by supporting ARIS simulations. Also we want to show how much people are informed about position and usage of this software by doing research among some big and medium size of Iranian organizations. The results show that the power and position of this software is very good, but people still have inertia to use it. Also as an applied sample in comparison with different modeling frameworks and methods ARIS is used to support rockets logistics research.
\end{abstract}

Index Terms-ARIS framework, ARIS platform, BPMN, missile equipments.

\section{INTRODUCTION}

Studing in 15 big and medium size organizations in Iran shows that none of them know about ARIS software and have not any tendency to use it. But, all of them have a high tendency to use simple software like MS Visio. One of their substantial excuse that they explain is that if it is enough good why other organizations (in Iran) do not use it? By considering their refusal we can get that in fact their specialists and users have not enough knowledge to use powerful capabilities and analyzing components of this tool. According to the research that includes number of academy schools, often they can not have any help to organizations too. Thus, these features are usually ignored. By looking to enterprise architecture's tools in this paper, we address the efficiency of ARIS.

\section{CRiteria of SElEction ARChitecture ToOlS}

There are different criteria for identification and selection of architectural tools. Most common tool selection's criteria are:

Technical and operational capabilities: platform, the performance and availability, user safety, software distribution, software release management, tools architecture and technical and operational requirements

Support Services: Supporting Unit 7 support, education, consulting and professional services, documentation, local

Manuscript received February 1, 2014; revised April 20, 2014.

Saiedeh Ghatrei is with Trust and Reliance General Trading LLC, Iran (e-mail: saiedeh.gh83@gmail.com). support groups, support service groups: supporting support unit, training, consulting and professional services, documentation, support local groups, News groups

Functional capabilities - specific aspects: supporting of analysis, supporting enterprise architecture frameworks, supporting the timing plan of enterprise architecture, simulation, reservoir management, models validation, support of languages, Standard methods and modeling techniques supporting review management

Functional capabilities - general aspects: User Interface, personalization, Inclusion and Integration, reporting, version 9 Management, Documentation Management, Manuals and Tutorials 10, Ordered library, Code Productivity, Commercial, Sellers' financial and credit status, Similar Experience in market, Strategic Partnerships, Major Expenditures, Operational Costs [1].

\section{FAMOUS TOOLS}

Table I shows the famous tools in the enterprise architecture.

Table II shows Market Leaders of enterprise architecture tools' development.

As indicated in the above tables, the three companies Troux, IBM / TeleLogic and IDS Scheer has been recognized as market leaders in both reports.

Table III shows Scoring to development tools of architecture by Forrester view.

\section{ARIS FACILITIES}

ARIS was introduced by IDS Scheer, the German company, to optimize business processes. ARIS provides the users with the facility to be certain about correct functionality of BPMN model by supporting ARIS simulator. ARIS (Architecture of Integrated Information Systems) was presented by German company of ADS Scheer for optimization of business processes. ARIS provides the organizations with comprehensive and integrated tools and techniques which are applied for organization strategy definition, design of organization business processes, implementation of process and control models and dynamic support of processes. All business services are defined absolutely explicit using ARIS and the available resources are assigned to the processes in less time and with more efficiency [2].

Table I shows the famous tools in the enterprise architecture.

As indicated in the above tables, the three companies Troux, IBM / TeleLogic and IDS Scheer has been recognized as market leaders in both reports.

Appendix I shows the cover of Architecture Development 
Frameworks by various tools [3].

TABLE I: THE FAMOUS TOOLS IN THE ENTERPRISE ARCHITECTURE [3], [4]

\begin{tabular}{ll|}
\hline Adaptive & Adaptive Enterprise Architecture Manager \\
\hline Casewise & Corporate Modeler Suite \\
\hline IDS Scheer & ARIS Platform \\
\hline Mega International & MEGA Modeling Suite \\
\hline Metastorm & Metastorm Provision \\
\hline IBM/TeleLogic & IBM Rational System Architect \\
\hline Troux & Troux 8 + Troux Product Family \\
\hline Alfabet & Planing IT .4.1 \\
\hline Sybase & PowerDesigner \\
\hline Salamander & MooD Platform \\
\hline QualiWare & QualiWare Enterprise Architecture \\
\hline iGrafx & iGrafx Enterprise Modeler \\
\hline BiZZdesign & BiZZdesign Architect \\
\hline
\end{tabular}

Table II shows Market Leaders of enterprise architecture tools' development.

TABLE II: MARKET LEADERS OF ENTERPRISE ARCHITECTURE TOOLS DEVELOPMENT [3]

\begin{tabular}{|l|l|}
\hline-- & Casewise \\
\hline IDS Scheer & IDS Scheer \\
\hline-- & Mega International \\
\hline-- & Meatstorm \\
\hline IBM/TeleLogic & IBM/TeleLogic \\
\hline Troux & Troux \\
\hline Alfabet & -- \\
\hline
\end{tabular}

\section{INTRODUCTION TO THE ARIS PLATFORM}

The ARIS products are aligned to the Business Process Management (BPM) lifecycle and offered in an integrated software solution grouped into four ARIS Platforms:

- The Strategy Platform,

- The Design Platform,

- The Implementation Platform,

- The Controlling Platform [5].

The system architecture of the ARIS Platform allows globally distributed organizations to set up common scenarios for designing, analysing, and optimising processes, IT, and software architectures [5].

Web-based products such as ARIS Business Optimizer, ARIS Business Architect, ARIS Business Designer, and ARIS UML Designer can access a centrally managed ARIS Business Server from anywhere in the world via a three-tier architecture. These products are designed to use utilise low bandwidth connections (e.g. dial-up, ISDN, etc.). Web-based clients can be started directly from within a Web browser or, alternatively, they can be installed as a desktop application manually or by automated software distribution. In both cases, any necessary client updates can be set up and controlled centrally to facilitate the rollout process [5].

ARIS is based around a central database for all modelling items (e.g. models, objects, connections, etc.) and all administration information. Everything described, designed and analysed within the different ARIS products is stored in this central data repository. All ARIS clients access the database server via the ARIS Business Server and thus work with a common database [5].

\section{What Models to USE}

Deciding what models to use can be somewhat of a black art. The EPC and FAD are the obvious models to use typically supported by Organizational charts, Entity Relationship Models and Application system type diagrams. In more complex business models the choice is not so straightforward. Some models are more useful than others, some objects are only available in certain types of model and the relationships between objects differ between models. A degree of experimentation is often necessary to decide which objects and models best suit your needs before you start modeling in earnest [5].

What can't be measured can't be optimized. So measure first and then optimize using ARIS Process Performance Manager (PPM). With their more tactical focus, process owners have to ensure process efficiency and quality. That can only be achieved by continuously monitoring actual processes and evaluating them in terms of quantity, time, cost, quality and risk. Process owners need to know their processes inside out and, thus, they need a comprehensive overview of the performance of their business workflows [6].

Use ARIS Process Performance Manager to:

- Automatically discover end-to-end processes for greater transparency

- Analyze historical processes to find weaknesses

- Benchmark processes to identify best practices

- Optimize team and collaboration structures using organizational analyses [6].

\section{KEY FEATURES}

1) Automated process discovery

2) Historical process analysis

3) Process benchmarking

4) Communication and organizational analysis

5) Easy link to ARIS MashZone [6]

\section{KEY BENEFITS}

1) Discover end-to-end processes automatically across different IT systems,

2) Monitor and analyze the performance and structure of business processes,

3) Identify best practices and specific optimization measures,

4) Optimize team and collaboration structures,

5) Easily analyze variations in standard processes,

6) Effortlessly model as-is processes that provides real-life visualization of processes [6].

\section{BPMN}

BPMN (Business Process Modeling Notation) is the modeling language of business which is the major basis of Business Process Modeling (BPM). This language was presented in 2002 by BPMI and is identified as a standard 
language since 2006. The main advantage of BPMN in comparison to other modeling languages is the existence of convertible diagrams to other executable languages such as BPEL (Business Process Execution Language) which is understandable by software systems. The main goal of BPMN is the preparation of notations and concepts which are perceptible for all business users such as business analysts, executive programming responsible and all the people who perform the act of management and control. BPMN is a tool which is applicable in the task of converting [2].

\section{EXtraction Phase Aris}

During the extraction phase ARIS PPM connects to an application system (SAP etc.) and reads relevant operational data. Nowadays most application systems use a relational database system as a repository for their operational data which can be accessed using well-established interfaces (e.g. JDBC). As a result of the extraction phase ARIS PPM obtains a set of data records which are structured as a tuple [7].

\section{MisSILE EQUIPMENTS AND ARIS}

Along with recent military involvement in equipment modernizing, missile equipments have been the main longdistance weapons for the modern military. For the new style missile equipments' tactical efficiency coming into being and maintenance, the one that equipment oneself has well supportability and planning sufficient support resources for the equipments have been the essential key [8].

The planning and execution of missile equipments' logistics support is a complicate system engineering. The first problem in the course of planning and execution is how to describe the system. For handling the essence and key constitution of the logistics support, avoiding the distortion of model, an effective system analyzing framework and modeling method should be chosen. Domestic and abroad academicians have a systemic research on the modeling theory. Especially, many mature system frameworks and methods have been used in the civil production manufacture, supply chain, such as CIM-OSA, PERA and ARIS frameworks [8].

\section{ARIS FRAMEWORK}

ARIS is the architecture of integrated information systems developed by the professor A.W. Scheer of Saarland University in German. ARIS house of Business Engineering (HOBE) [6] represents a general conceptual integrated model. Event-driven Process Chains (EPC), in which events and functions are combined to describe a chain of process, is the key of HOBE and connects all other views as a major factor in the Control of HOBE. HOBE is designed as a multi-view model in which each view has its lifecycle. It describes the relationship between function view, data view, organizational view and process view (Fig. 1). And the powerful software tool based on the modeling framework, ARIS toolset, has been developed and used in many companies. It enforces the modeling framework's practicability [8].

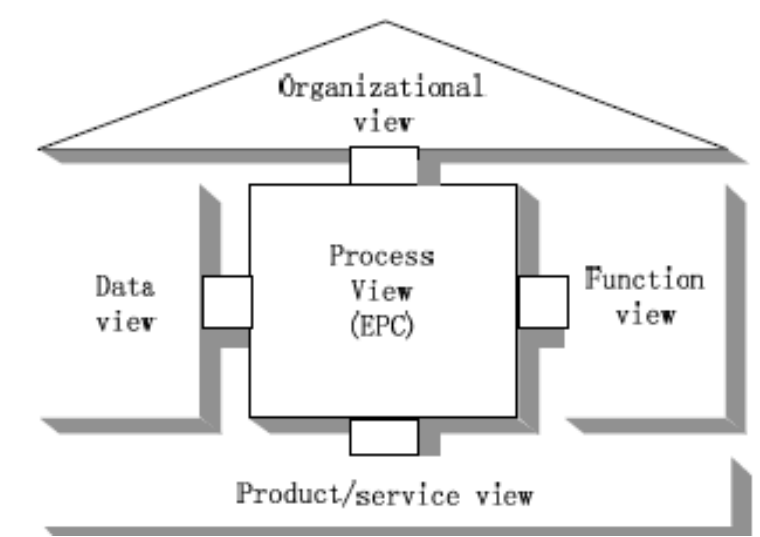

Fig. 1. ARIS modeling framework (Tingxue Xu, Wei Zhen, 2011) [8].

\section{COMPARISON OF MODELING FrAMEWORK}

As in Table III, It can be concluded from the comparison that the ARIS modeling framework has many dominances especially in the process modeling. It is easy to understand and operate, and it includes the whole information during the process modeling. So, for the missile equipments' logistics support process, the ARIS modeling framework is suitable. There is some other modeling frameworks, just like GRAIGIM, Zachman, IFW, which have been used in the enterprise process modeling field. They have the similar characters to the above four. So they do not be discussed because of the limit of the article length [8].

TABLE III: COMPARISON OF MODELING FRAMEWORK

\begin{tabular}{|c|c|c|c|c|c|}
\hline & \multirow[b]{2}{*}{ Index } & \multicolumn{4}{|c|}{ Modeling framework } \\
\hline & & $\begin{array}{c}C I M- \\
O S A\end{array}$ & PERA & $S C O R$ & $A R I S$ \\
\hline \multirow{5}{*}{ Frame } & Demension & three & two & two & three \\
\hline & Views & wholly & part & part & wholly \\
\hline & $\begin{array}{l}\text { Relasionship } \\
\text { among views }\end{array}$ & loosening & loosening & close & close \\
\hline & Phase & building & lifecycle & lifecycle & lifecycle \\
\hline & Opening & good & good & good & good \\
\hline \multirow{2}{*}{ application } & Models & multi & few & few & multi \\
\hline & Operationability & poor & general & general & powerful \\
\hline
\end{tabular}

\section{CONCLUSION}

By using this comparison software, the user becomes able to identify the best option according to the optimization criteria. Consequently, the user can identify weakness and poor models of processes.

The key benefits of the software can be considered as following:

1) Achieving end processes automatically through the different IT systems

2) Analyzing performance of structure of business processes

3) Identifying the best model and assessing its performance

4) Optimization of the co-working group

5) Simplification of variety of analysis in standard processes

6) Model is picturing processes in a real-mode.

Despite the high capabilities of ARIS Software and its 
position among the tops, it is unknown in Iranian organizations. It is recommended to raise the range of training in different organizations and awareness of individuals in various organizations. However, organizations' people should put their phobia of learning and using powerful and newer software aside and try to modernization of equipment facilities, and updating their information. But it does not mean that should provide the newest equipment, even, it is better to get help from informed consulters and choose the most suitable equipment and software for organization and do not fall behind the improvement progress.

\section{APPENDIX}

Appendix I shows the cover of Architecture Development Frameworks by various tools.

\begin{tabular}{|c|c|c|c|c|c|c|c|c|c|c|}
\hline Vendor & Products & Zachman & TOCAF & DoDAF & FEA & FEAF & $\begin{array}{l}\text { FEAF/ } \\
\text { TEAF }\end{array}$ & $\begin{array}{l}\text { Vendor- } \\
\text { Specific }\end{array}$ & Other & $\begin{array}{c}\text { Not } \\
\text { Specified }\end{array}$ \\
\hline Adaptive & $\begin{array}{l}\text { Adaptive EA Manager, } \\
\text { Business Process } \\
\text { Manager, IT Portfolio } \\
\text { Manager }\end{array}$ & $\checkmark$ & & & & $\checkmark$ & & & & \\
\hline Agilense & EA Webmodeler & & $\checkmark$ & $\checkmark$ & $\checkmark$ & & $\checkmark$ & $\checkmark$ & $\checkmark$ & \\
\hline Casewise & $\begin{array}{l}\text { Corporate Modeler } \\
\text { Enterprise Edition }\end{array}$ & $\checkmark$ & & $\checkmark$ & & & $\checkmark$ & $\checkmark$ & $\checkmark$ & \\
\hline Flashline & Flashline & & & & & $\checkmark$ & & & & \\
\hline Forsight & $\begin{array}{l}\text { Modeling and Validation } \\
\text { Tool }\end{array}$ & & & $\checkmark$ & & & & & & \\
\hline GoAgile & CoAgile MAP Product Suite & & & & & & & & & $\checkmark$ \\
\hline IDS Scheer & ARIS Process Platform & $\checkmark$ & $\checkmark$ & $\checkmark$ & $\checkmark$ & $\checkmark$ & $\checkmark$ & $\checkmark$ & & \\
\hline Logiclibrary & Logidex & & & & & & & & & $\checkmark$ \\
\hline $\begin{array}{l}\text { Mega } \\
\text { International }\end{array}$ & $\begin{array}{l}\text { Mega (Process, Architect, } \\
\text { Designer) }\end{array}$ & $\checkmark$ & & & & & & & & \\
\hline $\begin{array}{l}\text { Popkin } \\
\text { Software }\end{array}$ & System Architect Family & $\checkmark$ & $\checkmark$ & $\checkmark$ & & & & & & \\
\hline Proforma & Provision Modeling Suite & $\checkmark$ & & & & & & & $\checkmark$ & \\
\hline $\begin{array}{l}\text { Select Business } \\
\text { Solutions }\end{array}$ & $\begin{array}{l}\text { Select Component } \\
\text { Architect }\end{array}$ & $\checkmark$ & & & & & & & & \\
\hline Simon Labs & Simon Tool & $\checkmark$ & & & & & & $\checkmark$ & $\checkmark$ & \\
\hline TeleLogic & $\begin{array}{l}\text { Telelogic Enterprise } \\
\text { Architect for DoDAF }\end{array}$ & & & 1 & & & & & & \\
\hline Troux & Metis Product Family & $\checkmark$ & $\checkmark$ & $\checkmark$ & & & $\checkmark$ & & & \\
\hline
\end{tabular}

\section{REFERENCES}

[1] J. Schekkerman, "Enterprise architecture tool selection guide v5.0," Institute for Enterprise Architecture Developmets, 2009.

[2] S. Y. Barforoosh, S. M. Moghadam, and R. Nasiri, "Improvement of Test Management in BPMN with ARIS," in Proc. 2010 International Conference on Electronic Computer Technology (ICECT), Kuala Lumpur, pp. 59 - 62, May 7-10, 2010.

[3] A. Arbabi and H. Asgari, "Enterprise architecture development tool selection method," 2010.

[4] G. A. James. (2008). Magic Quadrant for Enterprise Architecture Tools. U.S.: Gartner RAS Core Research. [Online]. Available: http://www.uhlberg-advisory.info/uploads/media/1_GARTNER_Magi cQuadrant_EAReport2008.pdf

[5] R. Davis, ARIS Design Platform, New York, London: Springer, 2007, ch. 2, pp. 17-37.

[6] ARIS Process Performance Manager,SAG_ARIS_ProcPerfMngr_FS, SOFTWARE AG, Aug. 12, 2012.

[7] M. Fischer, “ARIS process performance manager,” pp. 307-310, 2008.

[8] T. $\mathrm{Xu}$ and W. Zhen, "Research on missile equipments' Logistics Support Process Modeling and Simulation by ARIS," in Proc. 2011 International Conference on Quality, Reliability, Risk, Maintenance, and Safety Engineering (ICQR2MSE), Xi'an, pp. 718-723, June 17-19, 2011.

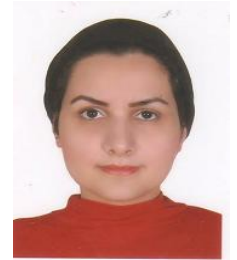

Saiedeh Ghatrei was born in Tehran, Iran on April 30, 1983. She Received B.s degree in computer science, software engineering from Islamic Azad University, Isfahan, Iran 2006. Then she received her M.s degree in information technology, information systems management from Shiraz University, Dubai campus, Iran 2013.

She worked as a C\# programmer in Alma Co,

Tehran, Iran 2006-2008, computer teacher in Education Way Institute, Dubai, UAE, from 2011 to 2012, an IT manager in Trust \& Reliance General Trading, Dubai, UAE, 2012 till now. She has participated in an International Conference on Digital Information Processing, e-Business and Cloud Computing (DIPECC 2013) in Dubai and presented 2 articles (1-Graphical Passwords, 2-Investigating Open Source ERPs).

She also participated in conference social innovations: Theoretical and Practical Insights at Mykolas Romeris University Research Days 2013 in Lithuania, and presented an article (the Effective Factors on Information Security Behavioral of Employees). 